Company's pamphlet on the A8. He states that "In addition, a mobile unit has been developed which can be readily mounted, dismounted, and transported to any required site". This implies that a second type of $A 8$ unit has been developed, whereas the pamphlet is merely pointing out the improvements in portability of the $A 8$ over its predecessor, the $A 6$.

Less than one quarter of the fifth chapter, "Aircraft for Survey", deals specifically with survey aircraft. Most of the chapter is concerned with two examples of survey projects in which aircraft were used. The first example is the air lift organized in the construction of the midCanada Line, an air detection unit, and the second, which takes up more than half the chapter, is a very general review of the work carried out by the Falklands Islands Dependencies Aerial Survey Expedition of 1955-57.

In the final chapter, "Examples of Air Survey", the author states that he refers "to some typical examples carried out in recent years". He then proceeds to review a paper, written twelve years ago, which discusses three non-typical "border line cases in which air survey was used". This is followed by a discussion on aerial survey for cadastral mapping and includes both techniques and a number of examples of work carried out. The author states, "Probably the most valuable and objective advice given to countries since the war on economic development has been contained in the reports prepared by the technical missions organized by the International Bank for Reconstruction and Development". Several references are made to these most valuable and useful reports, which deal particularly with the underdeveloped territories of the world. In almost every case they recommend the taking of aerial photographs for both map compilation, and as a source of information in the conservation and development of the natural resources. This is followed by some very useful information on photogeology taken from a paper by J. A. E. Allum. This paper is quoted as a reference though no mention is made of a very well written and informative book, Photogeology and Regional Mapping, by the same author. Finally, there is another review dealing with airborne geophysics in geological surveys.

Almost at the end of the book (the author's nineteenth) he reveals his reason for writing it when he comments: "The technical advances which have taken place in air survey over the past twenty years or so have received less publicity than was their due, with the result that there still exists widespread ignorance of the methods now employed in this field, and this book is an attempt to try and improve matters".

It is doubtful whether this attempt has been successful. W. Gordon Collins

\section{FIND A WORD}

Russian-English Translators Dictionary

A Guide to Scientific and Technical Usage. By Mikhail G. Zimmerman. Pp. 294. (New York: Plenum Press, 1967.) $\$ 12$.

THIs dictionary calls itself a translators' dictionary and the translators envisaged are those working on scientific and technical texts. What is ideally demanded of such translators is a good working knowledge of the Russian language together with a working knowledge of the subject of the book or article to be translated. This, in the majority of cases, is an impossible demand. If a specialist in a subject is also fluent in Russian he is more likely to devote his time to original work than to translation. Translators, then, are usually more familiar with ordinary Russian than with the scientific or technological terms of a particular discipline. It was to help such people that Dr Zimmerman conceived and executed his book. Has he succeeded in his very laudable purpose?
His method has been to take Russian words, teims or phrases, printed in Russian and arranged alphabetically. Each is followed by one or more example in English, drawn from technological or scientific writings, in which the words which could be translated by the Russian word or phrase are in heavy print. Where desirable there are cross references. It is an ingenious idea, but one which is extremely difficult to realize in practice. The present dictionary will be far more useful to technologists than to scientists, for only a small proportion of the terms is of interest to scientists. When these terms are spread over the numerous sciences the coverage for any one science is very thin indeed.

Another criticism concerns the inclusion of a large number of everyday prepositions, adjectives and adverbs, the use of which in a scientific or technological context differs little from their use in ordinary literary Russian. About nine pages (that is eighteen columns) deal with the use of $B$ (in) in various phrases. Quite a number of these are very obvious uses of the preposition in its generally accepted meaning. On page 101 seven quotations are given in connexion with the Russian word Krome (besides) The seventh quotation is: "There was little doubt about the good process performance of all the functional elements with the exception of the fluidized bed itself". It is difficult to see "with the exception of" as a synonym of "besides".

Examples such as these only emphasize the difficulties which beset an author who is "blazing a trail". With the ever growing volume of translations from Russian technological works, the need for a dietionary of this kind is clear and although, as Dr Zimmerman himself points out, this one is selective rather than exhaustive, it should, if used with discretion and common sense, prove a useful tool for the harassed translator.

S. I. TOMKEIEFF

\section{SOCIOLOGY FOR STUDENTS}

\section{Sociology}

An Introduction. Edited by Neil J. Smelser. Pp. xx + 744. (New York and London: John Wiley and Sons, Inc., 1967.) $68 s$.

ThIs volume is intended as an introductory text for students of sociology at university level. It consists of eleven chapters by well known authorities, which cover the main areas of specialization within modern sociology. There is an introduction and a concluding chapter by the editor, who has been successful in ensuring a high degree of consistency in both the matter and style of his collaborators' work. Unlike most of the other multi-author texts in the field, the book thus achieves a definite unity; the advantages of specialist contributions are not cancelled out by a lack of overall coherence. In view of this and the general quality of the writing, it is probable that during the next few years this text will become one of the most widely used on both sides of the Atlantic. For this reason it is perhaps all the more important that certain shortcomings-at least from the ideal-should be noted.

First, it must be said that despite the editor's express aim of providing an introduction to sociology on a rather higher intellectual level than is usual, the treatment of basic methodological and theoretical issues is often superficial. Many of the questions the intelligent newcomer to sociology is likely to ask about the nature of the subject as a science or discipline are not discussed in a way that will be found satisfying. Secondly, very little is said directly about the procedures through which sociological investi. gation is carried out. To regard this as a matter which can be left entirely to a separate text on "research techniques" now appears as somewhat old-fashioned. Thirdly, the overall view of sociology that the book presents carries a considerable American bias. Even accepting American pre-eminence in the field and the fact that the text is 